\title{
PENGEMBANGAN MODUL PEMBELAJARAN HIMPUNAN DENGAN PENDEKATAN KONTEKSTUAL UNTUK KELAS VII SMP
}

\author{
Ririn Dwi Agustin ${ }^{1}$ \\ ${ }^{1}$ Program Studi Pendidikan Matematika, IKIP Budi Utomo Malang \\ Email: ${ }^{1}$ ririndwiagustin85@gmail.com
}

\begin{abstract}
Abstrak
Tujuan penelitian ini adalah untuk menghasilkan modul matematika dengan pendekatan kontekstual untuk SMP kelas VII dan mendeskripsikan modul pada materi himpunan dengan pendekatan kontekstual untuk siswa kelas VII SMP yang ditinjau dari 3 nilai yaitu kevalidan, keefektifan, dan kepraktisan. Jenis penelitian ini merupakan penelitian pengembangan dengan model pengembangan ADDIE. yang meliputi analisis, desain, pengembangan, implementasi, evaluasi. Modul yang telah dikembangkan selanjutnya di validasi oleh 3 validator yaitu 2 dosen matematika IKIP Budi Utomo Malang dan 1 guru matematika sebagai ahli materi, ahli media, dan ahli bahasa. Hasil validasi menunjukkan skor rata-rata 3.06 dalam kategori valid dan angket respon siswa dinyatakan efektif dengan skor rata-rata $89 \%$ yang termasuk kategori sangat baik, dan modul dinayatakan praktis karena didalamnya terdapat petunjuk penggunaan modul, prasyarat, kunci jawaban, dll. Dari hasil penelitian maka dapat disimpulkan bahawa modul himpunan dengan pendekatan kontekstual layak untuk digunakan sebagai bahan ajar untuk siswa SMP kelas VII.
\end{abstract}

Kata Kunci: Modul, Himpunan, Pendekatan Kontekstual.

\begin{abstract}
The purpose of this study was to produce a mathematics module with a contextual approach to junior class VII and describe the material quality modules on the set with a contextual approach to class VII students are viewed from the 3 aspect of validity, effectiveness, and practicality. This type of research is the development of research with ADDIE development model. which includes analysis, design, development, implementation, evaluation. Modules have been developed further validated by the validator 3 is 2 mathematics lecturer Budi Utomo Malang Teachers' Training College and one teacher of mathematics as subject matter experts, media specialists, and linguists. The tests showed an average score of 3:06 in the category invalid and declared effective student questionnaire responses with an average score of $89 \%$ were categorized as excellent, and practical dinayatakan modules for which there are instructions for using the module, prerequisites, answer key, etc. From the research it can be concluded THAT module set with a contextual approach feasible to be used as teaching materials for junior high school students of class VII.
\end{abstract}

Keywords: Module, Association, Contextual Approach.

\section{PENDAHULUAN}

Belajar matematika yang kontektual merupan proses belajar antara pembawa pesandisini adalah guru dan siswa sebagai penerima pesan. Pembelajaran kontektual itu sendiri bermaksud untuk mempermudah siswa mengaitkan antara kognitif dengan kehidupan nyata. Menurut Mulyasa (2006) pembelajaran yang kontekstual memiliki keunggulan yaitu menjadikan pembelajaran di kelas menjadi damai dan menyenangkan, karena pembelajaran 
dilakukan secara direct dalam kehidupan nyata maka materi yang disampaikan akan masuk di memori siswa.

Menurut data observasi di sekolah dalam kaitannya dengan matematika, masih banyak siswa yang mengalami kesulitan dalam pembelajaran matematika. Banyak siswa yang kurang berminat dalam pembelajaran matematika maka hal itu akan berpengaruh pada prestasi siswa dalam proses pembelajaran. Masalah tersebut bisa diatasi dengan membuat pendidik yang kreatif dan inovatif yang mampu meningkatkan minatsiswa belajar matematika.

Selain itu temuan selama observasi di lapangan bahan ajar yang digunakan oleh siswa khususnya mata pelajaran matematika kurang menarik minat siswa, karena bahan ajar yang digunakan disekolah adalah bahan ajar yang sedikit materi dan tidak menerapkan contoh dalam kehidupan sehari-hari. Modul baru dengan pendekatan kontekstual sangat dibutuhkan. Diharapkan siswa akan mudah memahami buku yang dibacanya dan siswa juga termotivasi untuk belajar.

Guru di sekolah saat pembelajaran, sebagian besar hanya menggunakan LKS dan buku paket sebagai bahan ajar. Padahal pada kenyataannya, penggunakan LKS dan buku paket sebagai pendamping siswa dalam pembelajaran matematika kurang dapat memenuhi kebutuhan siswa dalam mencapai tujuan belajar matematika karena isinya masih bersifat penekanan pada materi, langsung diberikan rumus-rumus dan soal-soal tentang materi yang diberikan, sehingga siswa kurang bisa mengkaitkan problem yang ada pada bahan ajar dengan problem konkret. Berdasarkan permasalahan tersebut guru perlu membangun kreaktivitas siswa sendiri agar mampu membuat bahan ajar yang inovatif. Salah satunya adalah modul.

\section{Modul}

Modul merupakan suatu proses pembelajaran mengenai suatu topik bahasan tertentu yang dirancang yang diperuntukkan untuk siswa dan dipergunakan oleh guru yang terdapat petunjuk penggunaannya, menurut Mulyasa (2009) modul merupakan media untuk belajar secara individu yang didalmnya terdapat kumpulan ingatan disaat belajar yang dikemas untuk menyampikan tujuan pembelajaran.

Modul merupakan bahan ajar cetak yang dapat dibuat dengan mudah. Pengertian modul menurut Purwanto, dkk (2007) modul adalah bahan ajar yang dibuat dengan sistem melihat kurikulum yang dikai di sekolah dan dirancang dalam perangkat pembelajaran dengan maksud siswa dapat mendalami materi dengan efisien. Modul menjadi inti dalam menyajikan dan memberikan materi selama kegiatan pembelajaran berlangsung.

Modul merupakan sebuah buku yang dirancang dengan maksud agar siswa dapat secara individu walau tanpa guru. Modul juga terdapat komponen-komponen seperti pendahuluan, tujuan pembelajaran, tes awal, pengalaman belajar, sumber belajar, dan tes akhir.

\section{Pendekatan Kontektual}

Menurut Mulyasa (2006) pembelajaran kontekstual merupakan suatu dasar dalam belajar mengajar dikelas yang mengaitkan antara materi pembelajaran dengan kehidupan nyata, dan hasilnya siswa tersebut dapat mengaplikasikan dengan mengkaitkan dalam kehidupan sehari-hari.

Masnur (2011) pendekatan kontekstual merupakan salah satu pendekatan yang berlandasan pada pandangan belajar secara kontruktivisme, yaitu belajar tidak hanya menghafal tetapi membangun kognitif dan ketrampilan baru melalui fakta dalam kehidupan sehari-hari.

Menurut Majid (2013) pendekatan kontekstual mampu membantu guru mempermudah dalam mengaitkan materi dengan kehidupan nyata siswa sehingga mampu mengajak siswa membuat kaitan antara kognitifnya dengan kehidupan nyata yang memiliki karakteristik sebagai berikut: 

a. Kerja sama
b. Saling menyemangati
c. Menyenangkan, tidak jenuh
d. Belajar penuh semangat
e. Pembelajaran yang saling berkaitan
f. Sumber belajar
g. Siswa aktif
h. Diskusi dengan teman
i. Siswa kritis
j. Guru kreatif.

\section{METODE}

Penelitian pengembangan yang digunakan dalam penelitian ini adalah model pengembangan ADDIE. Model ini terdiri dari lima tahapan, yaitu sebagai berikut :

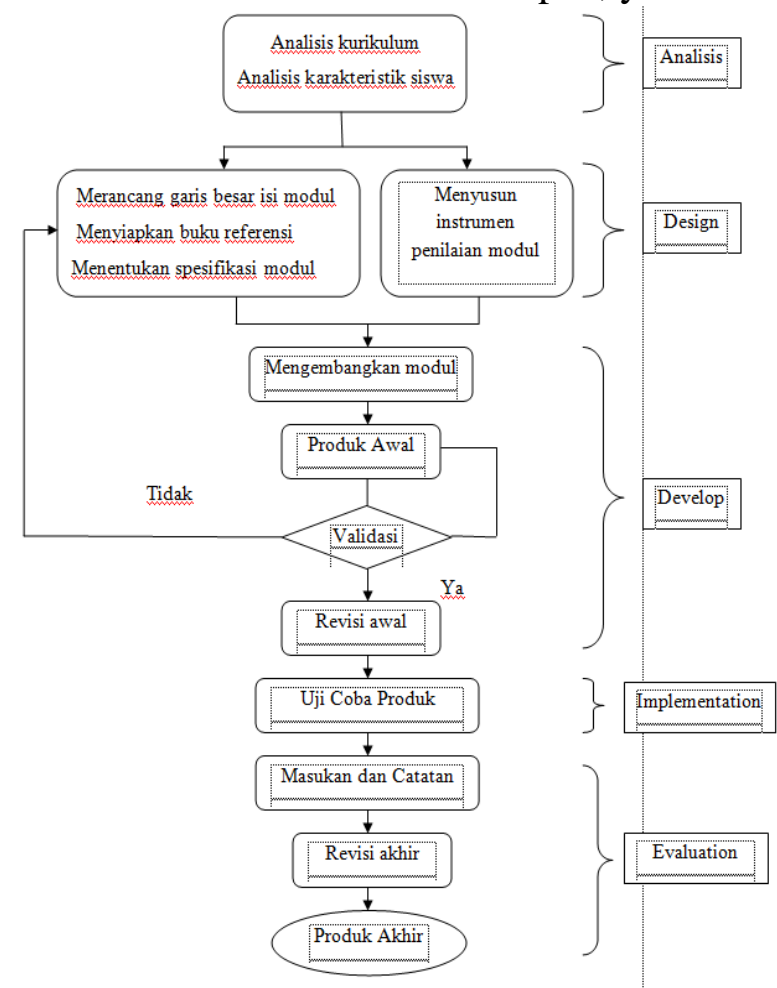

Gambar 1. Prosedur Pengembangan Modul

Penelitian ini dilaksanakan di SMP PGRI 6 Malang. Pemilihan tempat penelitian di SMP PGRI 6 Malang dikarenakan masih menggunakan buku paket dari pemerintah dan siswa kesulitan untuk belajar. Siswa kelas VII adalah subjek penelitian ini. Validasi yang diperlukan dalam penelitian terdiri dari 3 validator yaitu, ahli media, ahli materi, ahli bahasa, dan respon siswa. Instrumen yang digunakan adalah instrumen menilai kevalidan dan angket respon siswa. Angket respon siswa digunakan untuk mengetahui layak tidaknya modul untuk siswa.

1. Analisis untuk mengukur kevalidan

$$
\bar{x}=\frac{\sum x}{n}
$$

Keterangan:

$$
\bar{x} \quad=\text { skor rata-rata }
$$


$\sum x \quad=$ jumlah skor yang diperoleh

$n \quad$ = banyaknya butir pertanyaan

2. Angket respon siswa

$$
\mathrm{RS}=\frac{A}{B} \times 100 \%
$$

Keterangan:

RS = persentase siswa dengan kriteria tertentu

A $\quad=$ Jumlah skor yang di dapat

$\mathrm{B} \quad=$ jumlah skor maksimal

\section{HASIL DAN PEMBAHASAN}

Berikut rekapitulasi hasil penilaian modul oleh ahli materi, ahli media, dan ahli bahasa.

Tabel 4. Rekapitulasi Penilaian modul

\begin{tabular}{ccccc}
\hline No. & Ahli & Jumlah Skor & Rata-rata & Kategori \\
\hline 1 & Ahli materi & 63 & 2.73 & Valid \\
\hline 2 & Ahli media & 83 & 3.60 & Sangat Valid \\
\hline 3 & Ahli Bahasa & 66 & 2.86 & Valid \\
\hline & Kesimpulan & $\mathbf{2 1 5}$ & $\mathbf{3 . 0 6}$ & Valid \\
\hline
\end{tabular}

Modul dapat dikatakan layak/valid jika telah melalui tahap penilaian oleh ahli materi, ahli media, dan ahli bahasa. Setelah melalui tahappenilaian ahli materi, ahli media, dan hali bahasa maka modul himpunan ini dapat dinyatakan layak/valid untuk dikembangkan. Dilihat dari hasil validasi oleh ahli materi, didapatkan skor rata-rata 2.73 dengan kategori valid. Hasil oleh ahli media, diperoleh skor rata-rata 3.60 dengan kategori sangat valid. Dan ahli bahasa, diperoleh skor rata-rata 2.86 dengan kategori valid. Total skor dari semua validator diperoleh skor rata-rata 3.06 dengan kategori valid. Dan disimpulkan bahwa modul dinyatakan layak atau valid untuk digunakan.

Setelah melalui beberapa tahapan tadi selanjutnya modul diuji cobakan dengan memberikan angket respon siswa terhadap modul himpunan sebagai penilaian siswa terhadap modul pada penelitian ini. Modul diimplementasikan kepada 10 siswa kelas VII SMP PGRI 6 Malang. Berdasarkan analisis data pengisian angket respon siswa diperoleh hasil yang menunjukkan bahwa modul yang dikembangkan mendapatkan kategori sangat baik dengan persentase $89 \%$. Hal ini menunjukkan bahwa modul yang dikembangkan efektif digunakan sebagai bahan ajar. Modul dikatakan praktis karena didalamnya terdapat petunjuk penggunaan modul, prasyarat, kunci jawaban, dll. Dengan menggunakan pendekatan kontekstual maka modul dapat membantu siswa memahami materi matematika yang bersifat abstrak menjadi konkret atau nyata. Dengan demikian, maka siswa akan mudah memahami materi pembelajaran matematika terutama materi himpunan. 


\section{SIMPULAN DAN SARAN}

Berdasarkan hasil penelitian dan pembahasan terhadap modul yang dikembangkan, maka dapat diambil beberapa simpulan sebagai berikut.

1. Pengembanagan modul pada materi himpunan dengan pendekatan kontekstual untuk siswa kelas VII SMP menerapkan model pengembangan ADDIE yang terdiri:

a. Analisis yang meliputi analisis kebutuhan yaitu permasalahan saat pembelajaran matematika kurang mendukung sehingga dibutuhkannya bahan ajar berupa modul, analisis kurikulum yaitu menganalisis kurikulum untuk mengembangkan modul pada materi himpunan, dan analisis karakteristik siswa yaitu berdasarkan observasi kemampuan akademik siswa masih dibawah standar maka dari itu dirancang modul dengan semenarik mungkin.

b. Desain yang meliputi kerangka modul yaitu garis besar modul dan sistematika penyusunan materi, menetapkan desain tampilan sampul yaitu yang meliputi rancangan tampilan sampul, jenis huruf, ukuran huruf, spasi, dan pewarnaan modul, mengumpulkan referensi yaitu referensi yang dipakai saat membuat modul sebagai acuan membuat modul, dan menyusun instrument penilaian modul yaitu instrument yang digunakan dalam penelitian yaitu untuk ahli materi, ahli media, ahli bahasa, dan angket respon siswa.

c. Pengembangan yang meliputi penulisan draft modul yaitu garis besar isi modul dikembangkan menjadi sebuah bahan ajar modul, penyuntingan yaitu modul dikonsultasikan kepada dosen pembimbing sebelum di validasikan, validasi dan penilaian produk yaitu untuk meminta pertimbangan para ahli untuk meminta saran menganai kekurangan produk untuk perbaikan, dan revisi produk yaitu revisi modul digunakan untuk memperbaiki modul yang telah dikembangkan sesuai masukan dari para ahli.

d. Implementasi yaitu tahap dimana peneliti melakukan implementasi terhadap modul yang telah dihasilkan dengan cara menyebar angket respon siswa.

e. Evaluasi yaitu peneliti akan menganalisis hasil angket respon siswa terhadap modul himpunan.

2. Kualitas modul pada materi himpunan dengan pendekatan kontekstual untuk siswa kelas VII SMP yang telah dikembangkan adalah sebagai berikut.

a) Ditinjau dari kevalidan modul, yaitu oleh ahli materi, ahli media, dan ahli bahasa, modul yang dikembangkan peneliti memperoleh skor rata-rata 3.06 yang termasuk dalam kategori valid.

b) Ditinjau dari keefektifan modul, yaitu dari hasil angket respon siswa diperoleh skor rata-rata $89 \%$ yang termasuk kategori sangat baik.

\section{Saran}

c) Ditinjau dari kepraktisan modul, yaitu di dalam modul terdapat petunjuk penggunaan modul, prasyarat, kunci jawaban, dll.

Saran-saran yang dapat diberikan berdasarkan penelitian yang telah dilakukan adalah sebagai berikut.

1. Modul matematika materi himpunan dengan pendekatan kontekstual dapat digunakan sebagai salah satu pilihan bahan ajar untuk siswa kelas VII SMP.

2. Modul matematika materi himpunan dengan pendekatan kontekstual layak disempurnakan baik dari segi materi maupun desain tampilannya.

\section{DAFTAR RUJUKAN}

Chomsin, S. (2008). Panduan Menyusun Bahan Ajar Berbasis Kompetensi. Jakarta: Elex Media Komputindo. 
Dediknas. (2007). Pedoman Memilih Menyusun bahan Ajar dan Teks Mata Pelajaran. Jakarta: Depdiknas.

Dediknas. (2008). Panduan Pengembangan Materi Pembelajaran dan Standar Sarana dan Prasarana SMK/MA/SMA. Jakarta: BP Mitra Usaha Indonesia.

Dediknas. (2008). Pedoman Memilih Menyusun Bahan Ajar. Jakarta: BP Mitra Usaha Indonesia.

Hamalik, O. (2011). Kurikulum dan Pembelajaran. Jakarta: Bumi Aksara.

Hamdani. (2011). Strategi Belajar Mengajar. Bandung: CV Pustaka Setia.

Hudojo, H. (2005). Pengembangan Kurikulum dan pembelajaran Matematika. Malang: IKIP Malang.

Majid, A. (2013). Strategi Pembelajaran. Bandung: Remaja Rosdakarya.

Marsigit. (2009). Matematika 1 untuk SMP Kelas VII. Jakarta: Ghalia Indonesia.

Mulyasa, E (2009). Kurikulum yang Disempurnakan. Bandung: Remaja Rosdakarya.

Mulyasa, E. (2006). Implementasi Kurikulum 2004. Bandung: Remaja Rosdakarya.

Muslich, M. (2009). Pembelajaran Berbasis Kompetensi dan Kontekstual. Jakarta: Bumi Aksara.

Muslich, M. (2011). KTSP Pembelajaran Berbasis Kompetensi dan Kontekstual. Jakarta: Bumi Aksara.

Nasution. (2010). Berbagai Pendekatan dalam Proses belajar mengajar. Jakarta: Bumi Aksara.

Prastowo, A. (2011) Panduan Kreatif membuat Bahan Ajar Inovatif. Yogyakarta: Diva Press.

Prastowo, A. (2012). Panduan Membuat Bahan Ajar Inovatif, Menciptakan Metode Pembelajaran yang Menarik dan Menyenangkan. Yogyakarta: DIVA Press.

Purwanto. (2007). Pengembangan Modul. Jakarta: Depdiknas.

R. Soedjadi. (2000). Pendidikan Matematika di Indonesia Konstansi Keadaan Masa Kini Menuju Harapan Masa Depan. Jakarta: Direktorat Jendral Pendidikan Tinggi.

Runtukahu \& Tombokan.. (2014). Pembelajaran Matematika Dasar Bagi Anak Berkesulitan Belajar. Yogyakarta: Ar-Ruzz Media.

Sanjaya \& Wina. (2009). Strategi Pembelajaran Berorientasi Standar Proses Pendidikan. Jakarta: Kencana.

Sardiman. (2005). Media Pendidikan, Pengembangan, dan Pemanfaatannya. Jakarta: Rajawali.

Sugiyono. (2013). Metode Penelitian Pendidikan. Bandung: Alfabeta.

Suherman \& Erman. (2003). Strategi Pembelajaran Matematika Kontemporer. Bandung: Universitas Pendidikan Indonesia.

Wijaya, A. (2012). Pendidikan Matematika Realistic Suatu Alternative Pendekatan Pembelajaran Matematika. Yogyakarta: Graha Ilmu. 